\title{
HVOF Yöntemi ile Gerçekleştirilen Stellite-1 Kaplamaların Aşınma Kayıplarının Yapay Sinir Ağları ile Tahmini
}

\author{
Turan GÜRGENÇ* \\ Otomotiv Mühendisliği, Teknoloji Fakültesi, Fırat Üniversitesi, Elazı̆̆, TÜRKIYYE \\ tgurgenc@firat.edu.tr
}

\begin{abstract}
Öz: Bu çalıșmada, yüksek hızlı oksi-yakıt püskürtme (HVOF) tekniği ile Stellite-1 tozu ile kaplanan AZ91D magnezyum alaşımının aşınma davranışı araştırıldı. Deney numunelerinin aşınma kayıpları farklı yük ve kayma mesafeleri için laboratuvar deneyleri ile ölçüldü ve bu değerler yapay sinir ağları (YSA) modellemede veri seti olarak kullanıldı. Çalışmada kullanılan veri seti 108 adet aşınma kaybı verisinden oluşmaktadır. YSA modellemede giriş parametreleri olarak; numune çeşidi, ortalama sertlik $\left(\mathrm{HV}_{0.1}\right)$, yüzey pürüzlülüğü $(\mathrm{Ra}=\mu \mathrm{m})$, normal kuvvet $(\mathrm{N})$ ve kayma mesafesi $(\mathrm{m})$ kullanıldı. Çıkış parametresi olarak ise aşınma kaybı (AK) miktarları (mg) kullanıldı. YSA ile aşınma kayıplarının tahmininde başarım oranı 0.9793' dür.
\end{abstract}

Anahtar kelimeler: HVOF, Yüzey kaplama, Stellite-1, Aşınma, Yapay sinir ağları, Aşınma kaybı tahmini.

\section{Prediction of Wear Losses of Stellite-1 Coatings Performed by HVOF Method with Artificial Neural Networks}

\begin{abstract}
In this study, the wear behavior of AZ91D magnesium alloy coated with Stellite-1 powder by high speed oxy-fuel spraying (HVOF) technique was investigated. The wear losses of the test samples were measured by laboratory tests for different loads and sliding distances and these values were used as data set in artificial neural networks (ANN) modeling. The data set used in the study consists of 108 wear loss data. As the input parameters in ANN modeling; sample type, average hardness $\left(\mathrm{HV}_{0.1}\right)$, surface roughness $(\mathrm{Ra}=\mu \mathrm{m})$, normal force $(\mathrm{N})$ and sliding distance $(\mathrm{m})$ were used. Wear loss $(\mathrm{WL})$ amounts $(\mathrm{mg})$ were used as output parameters. The success rate is determined as 0.9793 in the prediction of wear losses with ANN.
\end{abstract}

Key words: HVOF, Surface coating, Stellite-1, Wear, Artificial neural network, Wear loss prediction.

\section{Giriş}

Magnezyum alaşımları, düşük yoğunlukları, yüksek özgül dayanıklılıkları ve üstün biyouyumlulukları nedeniyle havacılık, otomotiv endüstrilerinde ve biyolojik implantlarda son yıllarda oldukça büyük ilgi görmektedir [1]. Bu gibi olumlu özelliklerinin yanında magnezyum alaşımlarının korozyon ve aşınma dirençleri oldukça düşüktür. Bu olumsuzluklar magnezyum alaşımlarının kullanım alanlarını oldukça sınırlandırmaktadır [2, 3]. Malzeme yüzeylerini korozyon ve aşınmaya karşı dayanıklı hale getirmede kullanılan en etkin metot yüzey kaplamadır. Çeşitli yüzey kaplama metotları olmakla birlikte, sıklıkla kullanılan metotlardan biri termal sprey kaplama yöntemidir [4]. Uygulamada alev sprey [5], plazma sprey [6], ark sprey [7], HVOF [8] ve soğuk sprey [9] gibi spreyle yüzey kaplama yöntemleri mevcuttur. Bu yöntemler içerisinde HVOF’ nin düşük porozite, düşük oksitlenme, yüksek bağlanma mukavemeti, mükemmel korozyon ve aşınma direnci gibi avantajları mevcuttur [10, 11]. Magnezyum alaşımlarının yüzeyi HVOF yöntemi ile literatürde, WC-12Co [12], Al-SiC [13], 316L paslanmaz çelik [14] ve $\mathrm{Al} / \mathrm{SiCp}$ [15] gibi yüzey kaplama tozlarıyla kaplanmıştır.

Stellite kaplama ile malzeme yüzeylerinde oldukça sert ve aşınma dirençli kaplama tabakaları meydana getirilmektedir. Bunun nedeni Stellite kaplamayla yüzeyde meydana getirilen sert karbürlerdir. Stellite tozlarıyla gerçekleştirilen kaplamaların aşınma dayanımları oldukça yüksektir [16].

Bir malzemenin aşınması temas geometrisine, yüzey pürüzlülüğüne, mikroyapısal özelliklere, tane boyutlarına, kırılma tokluğuna, hıza, yüke, sıcaklığa, süreye, çevreye ve yağlamaya bağlıdır. Tüm bu faktörler nedeniyle aşınma oldukça kompleks bir sistemin fonksiyonudur [17]. Bu nedenle aşınma deneyleri maliyetli ve uzun zaman alan deneylerdir. Aşınma miktarlarının deney yapılmadan yapay zeka yöntemleri kullanılarak tahmin edilmesiyle aşınma deneylerinde ortaya çıkan iş gücü, maliyet ve zaman kaybının önüne geçilebilecektir [18]. Malzemelerin aşınmasını tahmin etme yeteneği, yeni malzemelerin farklı teknolojilere başarılı bir şekilde uygulanması için çok önemli olan evrensel bir yaklaşımdır [17]. Aşınmayı tahmin etmede en sık kullanılan

\footnotetext{
* Sorumlu yazar: tgurgenc@ firat.edu.tr. Yazarın ORCID Numarası: 0000-0002-7678-2673
} 
yöntemlerden biri yapay sinir ağlarıdır (YSA). YSA modellemesi biyolojik sinir sisteminden ilham almıştır ve çok çeşitli karmaşık bilimsel ve mühendislik problemlerini çözmek için günümüzde sıklıkla kullanılmaktadır. Bu matematiksel teknik, örnek olarak öğrenme ve örnek olaylardan bir dizi giriş ve çıkış değerindeki kalıpları tanıma yeteneği nedeniyle fiziksel modellerle açıklanması zor olan herhangi bir korelasyonun simülasyonları için oldukça kullanışlıdır [19]. Literatürde farklı malzemelerin ve kaplamaların aşınma davranışlarını belirlemede YSA başarılı bir şekilde kullanılmıştır [19-23].

Bu çalışmada yüzeyi HVOF yöntemi ile farklı parametrelerde Stellite-1 tozu ile kaplanan magnezyum alaşımının aşınma kaybı verilerinden yararlanılmıştır. Aşınma kayıp miktarları farklı yük ve mesafeler için deneysel olarak tespit edilmiş ve aşınma kayıplarının tahmininin YSA kullanılarak yapılabileceği gösterilmiştir. Yapılan çalışmada ilk bölümde çalışma hakkında kısaca bilgi verilmiş, ikinci bölümde deneysel olarak aşınma kaybı verilerinin nasıl elde edildiği detaylıca açıklanmış, üçüncü bölümde YSA ile ilgili bilgi verildikten sonra dördüncü bölümde tartışma ve sonuçlara yer verilmiştir. Beşinci ve son bölümde ise çalışmada elde edilen genel sonuçlar açıklanmıştır.

\section{Deneysel Verilerin Elde Edilmesi}

Mevcut çalışmada, $20 \mathrm{~mm}$ çapında ve $50 \mathrm{~mm}$ uzunluğunda AZ91D magnezyum alaşımı altlık malzeme olarak kullanılmıştır. Numuneler ilk olarak 15 dakika ultrasonik banyoda etanol ile temizlenmiş ve daha sonra yine ultrasonik banyoda saf su ile 15 dakika durulanmıştır. Numunelerin üzerindeki nem sıcak hava ile giderilmiştir. Kaplamadan önce yüzeyler 5 bar basınçta $\mathrm{Al}_{2} \mathrm{O}_{3}$ kumu ile kumlanmış ve pürüzlendirilmiştir. Yüzeyler GTV marka Stellite-1 tozu ile (Tablo 2.1) HVOF yöntemi kullanılarak Tablo 2.2' de verilen parametrelerde kaplanmıştır. Kaplanan numunelerin kaplama yüzeyi SEM görüntüleri Şekil 2.1' de görülmektedir. Kaplama yüzeylerinin yüzey pürüzlülük değerleri Mitutoyo SJ-201 profilometre kullanılarak belirlenmiştir. Ölçümler kaplamanın 10 farklı noktasından gerçekleştirilmiş ve ortalaması alınarak yüzey pürüzlülük değerleri hesaplanmıştır (Şekil 2.2). Kaplanan numuneler tel erozyon yöntemi ile aşınma deneylerinde kullanılmak üzere 10 mm' lik parçalara bölünmüştür. Kesilen parçalar 15 dakika ultrasonik banyoda etanol ile temizlenmiş, daha sonra yine ultrasonik banyoda saf su ile durulanmış ve üzerindeki nem sıcak hava ile giderilmiştir.

Tablo 2.1. Stellite-1 özellikleri.

\begin{tabular}{|c|c|c|c|c|}
\hline Element & $\mathrm{Cr}$ & $\mathrm{W}$ & $\mathrm{C}$ & $\mathrm{Co}$ \\
\hline Kimyasal kompozisyon (ağ.-\%) & 30 & 12 & 1.5 & bal. \\
\hline Toz boyutu & \multicolumn{5}{|c|}{$-53+20 \mu \mathrm{m}$} \\
\hline
\end{tabular}

Tablo 2.2. Plazma sprey kaplama

\begin{tabular}{|c|c|c|c|c|c|}
\hline Numune & $\begin{array}{c}\text { Oksijen debisi } \\
\text { (l/dk.) }\end{array}$ & $\begin{array}{c}\text { Propan } \\
\text { debisi (1/dk.) }\end{array}$ & $\begin{array}{c}\text { Sprey mesafesi } \\
\text { (mm) }\end{array}$ & $\begin{array}{c}\text { Toz besleme } \\
\text { oranı (g/dk.) }\end{array}$ & $\begin{array}{c}\text { Taşııcı gaz debisi } \\
\text { (l/dk.) }\end{array}$ \\
\hline S1 & 250 & 60 & 260 & \\
\hline S2 & 250 & 60 & 270 & \\
\hline S3 & 250 & 60 & 280 & \\
\hline S5 & 200 & 50 & 260 & \\
\hline S6 & 200 & 50 & 270 & \\
\end{tabular}




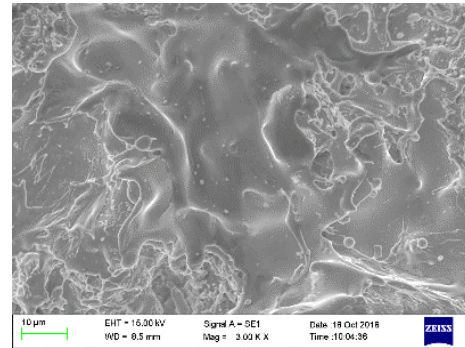

a) $\mathrm{S} 1$

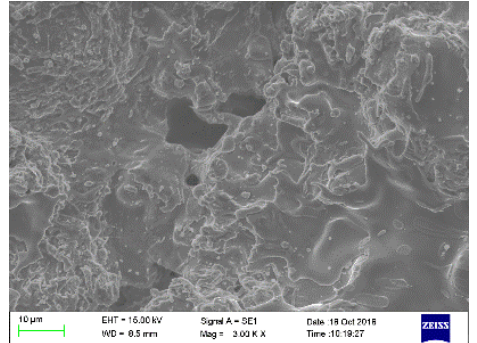

d) S4

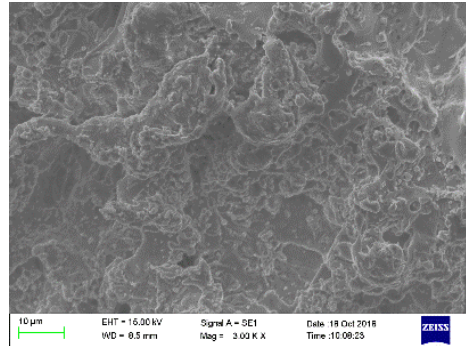

b) $\mathrm{S} 2$

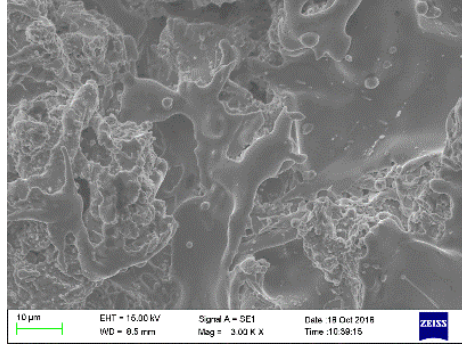

e) S5

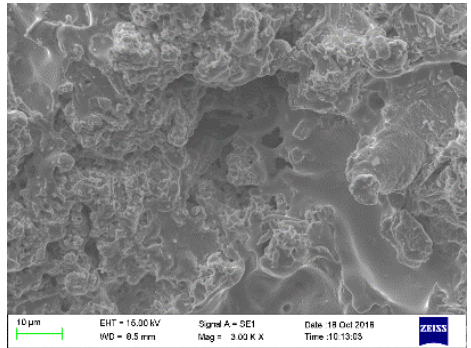

c) $\mathrm{S} 3$

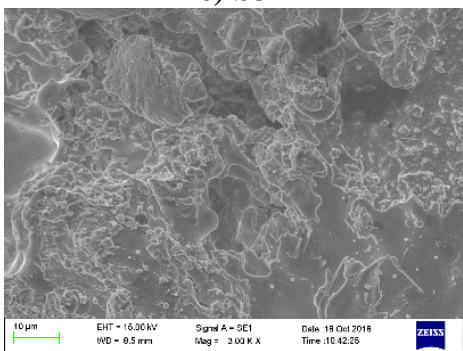

f) S6

Şekil 2.1. HVOF ile Stellite-1 kaplı yüzeylerin SEM fotoğrafları (x3000).

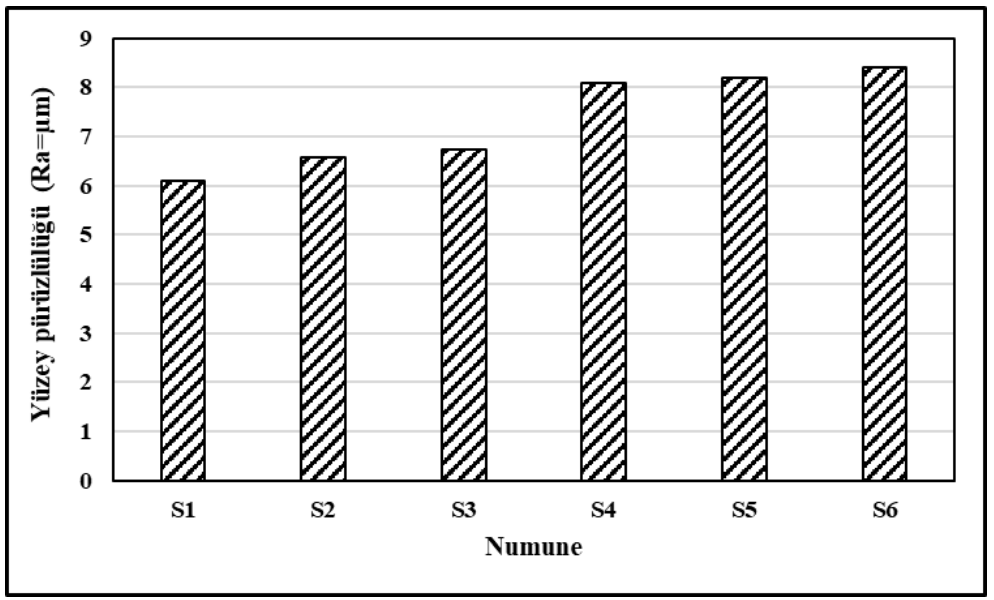

Şekil 2.2. Yüzey pürüzlülük değerleri.

Kaplama tabakalarının sertlikleri 5 farklı noktadan ölçülen değerlerin ortalaması alınarak bulunmuştur. Her ölçüm 10 saniye boyunca 100 g kütle uygulanarak yapılmıştır. Şekil 2.3' her bir kaplamaya ait ortalama sertlik değerleri görülmektedir. Aşınma deneyleri disk-on-disk tip kuru kaymalı aşınma deney cihazında oda sıcaklığında gerçekleştirilmiştir. Aşındırıcı olarak $40 \mathrm{~mm}$ çapında AISI 52100 yatak çeliği kullanılmış ve aşınma testi sırasıyla 5, 7.5, $10 \mathrm{~N}$ normal yük, $150 \mathrm{~m}$ kayma mesafesi ve $100 \mathrm{~mm} / \mathrm{s}$ kayma hızı ile yapılmıştır. Her $25 \mathrm{~m}$ ' de bir aşınma kayıpları $10^{-5}(\mathrm{~g})$ hassasiyetindeki terazi ile ölçülmüştür. Her test üç kez tekrar edilmiş ve bunların ortalaması alınmıştır. Şekil 2.4-6' da farklı yük değerlerinde kayma mesafesine bağlı aşınma kayıpları görülmektedir. Kaplanmış numunelerin aşınma kayıpları kaplamaların sertliği arttıkça sertliğin aşınma direnci üzerindeki olumlu etkisinden dolayı azalmıştır. Aşınma direnci tüm yük değerlerinde en yüksek olan numune S1 ve en düşük olan numune S6' dır. Aşınma miktarları kaplama sırasındaki ısı enerjisinin azalmasıyla ve sprey mesafesinin artmasıyla artmıştır. Bunun nedeni olarak bu parametrelerde kaplama tozlarının yeterince ergimemesi ve buna bağlı olarak kaplamalardaki boşluk ve gözeneklerin artması gösterilebilir. Yine yük arttıkça aşınma miktarları da artmıştır. 


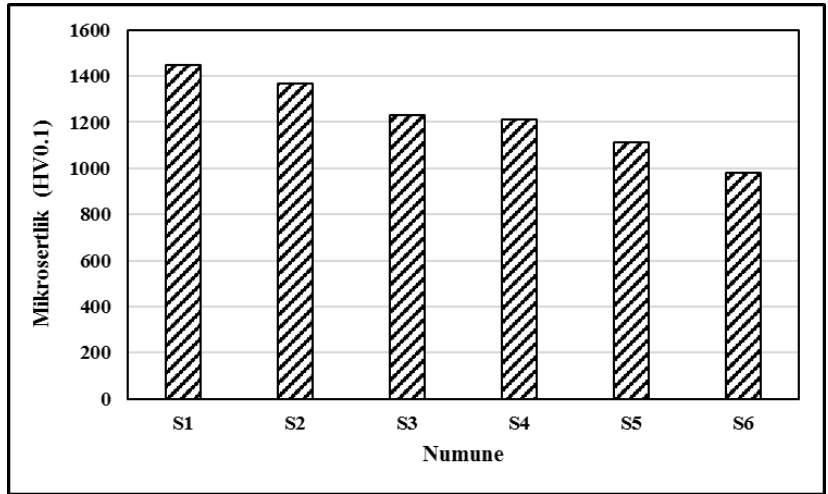

Şekil 2.3. Numunelerin kaplama tabakası ortalama sertlikleri.

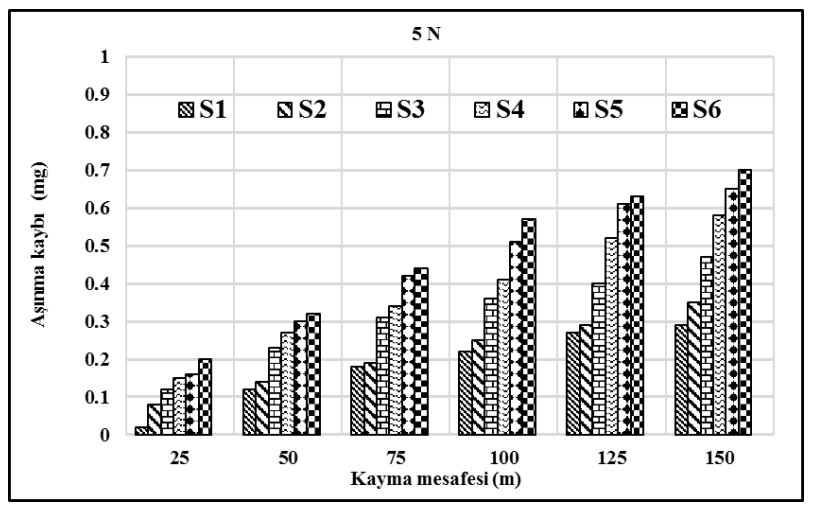

Şekil 2.4. $5 \mathrm{~N}$ yükte kayma mesafesine bağlı aşınma kayıpları.

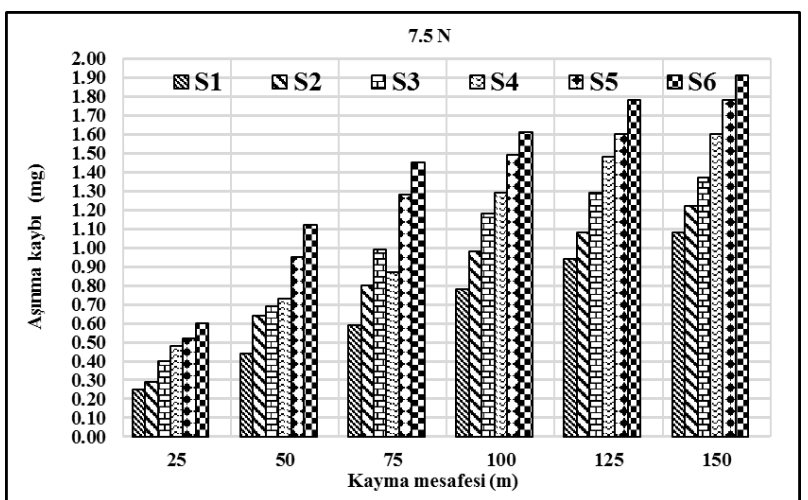

Şekil 2.5. 7.5 N yükte kayma mesafesine bağlı aşınma kayıpları. 


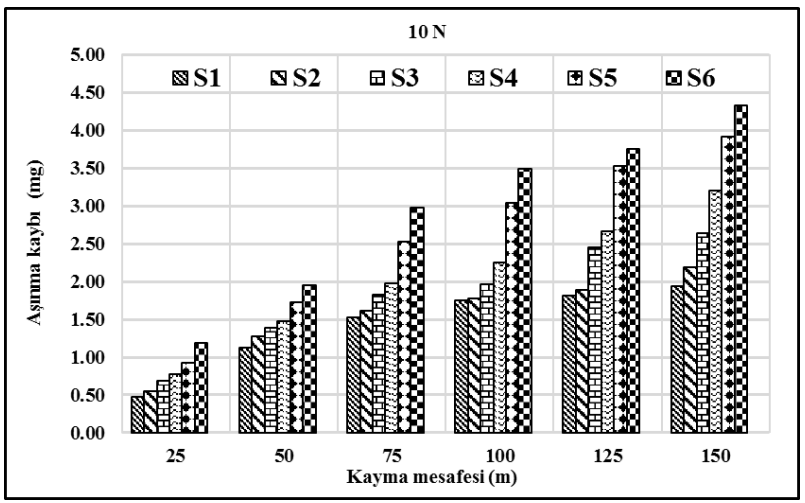

Şekil 2.6. $10 \mathrm{~N}$ yükte kayma mesafesine bağlı aşınma kayıpları.

\section{Yapay Sinir Ağları (YSA)}

İnsan beyninden esinlenerek ortaya çıkan yapay sinir ağları birçok farklı alanda regresyon analizi için başarı ile uygulanmaktadır. YSA birçok farklı veri setinde uygulanabilmektedir. Uygulandığı veri setinde, verilerin birbirleri ile olan ilişkileri çıkarabilmekte ve uzmanlar tarafından hesaplanması ya da bulunması zor değerleri tahmin edebilmektedir [24]. Yapay sinir ağları doğrusal olmayan fonksiyonları modellemek için kullanılan ve genelleştirilebilen bir yöntemdir. Doğrusal olmayan her işlevi istenen doğruluk düzeyinde tahmin edebilmektedir. Yapay sinir ağlarının doğrusal olmayan fonksiyonları tahmin etmedeki genelleştirilebilir ve uygulanabilir olması yapay sinir ağlarını veri işlemesi için paha biçilmez yöntemlere dönüştürmektedir [25] . YSA, insan sinir sistemi hücrelerine benzer şekilde modellenen yapay nöronlardan oluşmaktadır. Her yapay nöron birbirine belirli bir ağırlıkla bağlanmaktadır. Bu yapay nöronlar ağın katmanlarında toplanmaktadır. Bir katmanın çıktısı bir sonraki katmanın girişini oluşturmaktadır. Böylece, YSA sorunu öğrenir ve çıktı ya da çıktıları üretebilmektedir. Şekil 3.1' de tipik bir YSA nöron modeli görülmektedir [26].

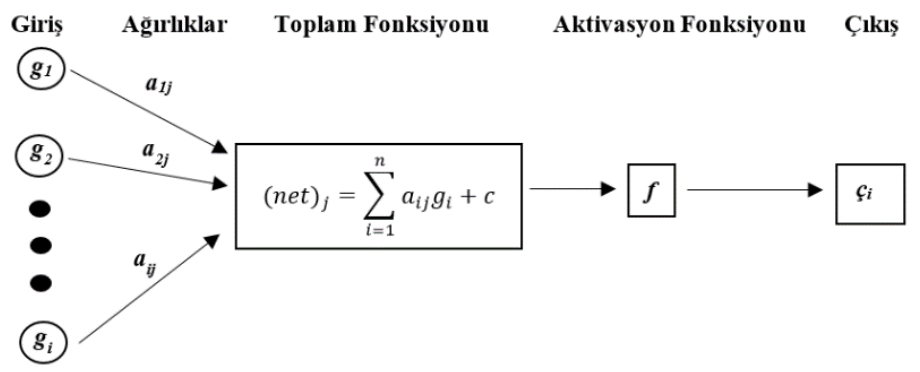

Şekil 3.1. YSA nöron modeli.

Yapay sinir ağı modeli; girişler, ağılıklar, toplam, aktivasyon fonksiyonu ve çıkış veya çıkışlardan oluşmaktadır. Temel yapay sinir ağı modelinin hesaplanması aşağıdaki Denklem 1' de verilmiştir.

$(\text { net })_{j}=\sum_{i=1}^{n} a_{i j} g_{i}+c$

Aktivasyon Fonksiyonu: Sinir ağında problemi çözme yeteneği ve verimliliğii, büyük ölçüde ağ yapısına ek olarak ağ tarafindan kullanılan aktivasyon fonksiyonuna bağlıdır. Aktivasyon fonksiyonunun seçimi, ağın yakınsama hızı üzerinde büyük etkiye sahiptir. Aktivasyon fonksiyonunun seçimi farklı fiili probleme göre değişmektedir [27]. Bir çok farklı aktivasyon fonksiyonları bulunmaktadır. Bu çalışmada aktivasyon denklemi olarak sigmoid kullanılmıştır. Aşağıda verilen Denklem 2 bu çalışmada kullanılan aktivasyon fonksiyonun denklemidir.

$f(n e t)_{j}=\frac{1}{1+e^{-\alpha(n e t) j}}$ 


\section{Tartışma ve Sonuçlar}

Yapılan çalışmada giriş parametreleri olarak 5 farklı özellik kullanılmıştır. Bunlar numune çeşidi, ortalama sertlik $\left(\mathrm{HV}_{0,1}\right)$, yüzey pürüzlülüğü $\left(\mathrm{R}_{\mathrm{a}}=\mu \mathrm{m}\right)$, normal kuvvet $(\mathrm{N})$ ve kayma mesafesidir $(\mathrm{m})$. Çıkış parametresi olarak HVOF yöntemi ile Stellite-1 tozu ile kaplanan AZ91D magnezyum alaşımının aşınma kaybı (AK) miktarları (mg) tahmin edilmeye çalışılmıştır. Yapay sinir ağının modellenmesi için Fırat Üniversitesi’ne ait olan lisanslı Matlab programı kullanılmıştır. Yapay sinir ağının modellenmesinde gizli nöron sayısı 10 olarak alınmış, öğrenme algoritması olarak levenberg-marquardt yöntemi kullanılmıştır. Yapılan çalışmada veri seti; eğitim seti, validasyon seti ve test seti olarak üçe ayrılmıştır. Veri setinin yüzde 70' ini eğitim seti (76), yüzde 15' ini validasyon (16) ve yüzde 15 'ini test seti (16) oluşturmaktadır. Tablo 4.1' de test verisini oluşturan yüzde 30' luk kısmın laboratuvar ortamında gerçekleştirilen kuru kaymalı aşınma deneyi sonucunda elde edilen hedef değerleri ve yapay sinir ağı sonucunda bulunan tahmin sonuçları verilmiştir. Görüldüğü gibi tahmin sonuçları deneysel verilere yakın değerlerdedir.

Oluşturulan modelin test edilmesi için regresyon analizinde sıklıkla kullanılan test metriklerinden R-değeri (Denklem 3), Ortalama Mutlak Hata (OMH) Denklem 4, Ortalama Kare Hata (OKH) Denklem 5 ve Kök Ortalama Kare Hata (KOKH) Denklem 6 değerleri kullanılmıştır. OMH iki sürekli değişken arasındaki farkın ölçüsüdür. $\mathrm{OMH}$, her gerçek değer ile veriye en iyi uyan çizgi arasındaki ortalama dikey mesafedir. OKH bir regresyon eğrisinin bir dizi noktaya ne kadar yakın olduğunu söyler. OKH, bir YSA modelinin performansını ölçer, her zaman pozitif değerlidir ve OKH değeri sıfira yakın olan daha iyi bir performans gösterdiği söylenebilir. KOKH YSA modelinin, tahminle içinin tahmin ettiği değerler ile gerçek değerleri arasındaki uzaklığın bulunmasında sıklıkla kullanılan, hatanın büyüklüğünü ölçen bir metriktir. KOKH tahmin hatalarının standart sapmasıdır. Parametrelere ait denklemler aşağıda verilmiştir.

$$
\begin{aligned}
& R-\text { de ğeri }=\frac{\sum_{i=1}^{n}\left(x_{i}-\bar{x}\right)\left(y_{i}-\bar{y}\right)}{\sqrt{\sum_{i=1}^{n}\left(x_{i}-\bar{x}\right)^{2}} \sqrt{\sum_{i=1}^{n}\left(y_{i}-\bar{y}\right)^{2}}} \\
& O M H=\frac{1}{n} \sum_{j=1}^{n}\left|e_{j}\right| \\
& O K H=\frac{1}{n} \sum_{j=1}^{n} e_{j}^{2} \\
& \mathrm{KOKH}=\sqrt{\frac{\sum_{j=1}^{n} e_{j}^{2}}{n}}
\end{aligned}
$$

\begin{tabular}{|c|c|c|c|c|c|c|c|}
\hline & $\begin{array}{c}\text { Numune } \\
\text { No. }\end{array}$ & $\begin{array}{c}\text { Ortalama } \\
\text { sertlik } \\
\left(\mathbf{H V}_{0.1}\right)\end{array}$ & $\begin{array}{c}\text { Yüzey } \\
\text { pürüzlülüğ̈̈ } \\
\left(\mathbf{R}_{\mathrm{a}}=\mu \mathbf{m}\right)\end{array}$ & $\begin{array}{c}\text { Normal } \\
\text { Kuvvet } \\
\text { (N) }\end{array}$ & $\begin{array}{c}\text { Kayma } \\
\text { mesafesi } \\
(\mathbf{m})\end{array}$ & Deneysel AK (mg) & $\begin{array}{c}\text { Tahmin } \\
\text { edilen } \\
\text { AK }(\mathbf{m g})\end{array}$ \\
\hline 1 & 4 & 1212 & 8.078 & 10 & 75 & 1.98 & 1.85 \\
\hline 2 & 4 & 1212 & 8.078 & 10 & 100 & 2.25 & 2.26 \\
\hline 3 & 4 & 1212 & 8.078 & 10 & 125 & 2.67 & 2.69 \\
\hline 4 & 4 & 1212 & 8.078 & 10 & 150 & 3.20 & 3.19 \\
\hline 5 & 5 & 1110 & 8.194 & 10 & 25 & 0.92 & 1.43 \\
\hline 6 & 5 & 1110 & 8.194 & 10 & 50 & 1.72 & 2.05 \\
\hline 7 & 5 & 1110 & 8.194 & 10 & 75 & 2.53 & 2.57 \\
\hline 8 & 5 & 1110 & 8.194 & 10 & 100 & 3.04 & 3.01 \\
\hline 9 & 5 & 1110 & 8.194 & 10 & 125 & 3.53 & 3.45 \\
\hline 10 & 5 & 1110 & 8.194 & 10 & 150 & 3.92 & 3.92 \\
\hline 11 & 6 & 982 & 8.398 & 10 & 25 & 1.19 & 1.22 \\
\hline 12 & 6 & 982 & 8.398 & 10 & 50 & 1.95 & 1.93 \\
\hline 13 & 6 & 982 & 8.398 & 10 & 75 & 2.98 & 2.57 \\
\hline 14 & 6 & 982 & 8.398 & 10 & 100 & 3.49 & 3.16 \\
\hline 15 & 6 & 982 & 8.398 & 10 & 125 & 3.75 & 3.74 \\
\hline 16 & 6 & 982 & 8.398 & 10 & 150 & 4.33 & 4.33 \\
\hline
\end{tabular}

Tablo 4.1. Deneysel ve YSA ile tahmin edilen aşınma kayıplarının karşılaştırılması. 
YSA modelinin test edilmesi sonucunda bulunan değerler Tablo 4.2.' de ve regresyon grafiği ise Şekil 4.1' de verilmiştir. Tablo 4.2' de görüldüğü gibi çalışmanın sonucunda R-değeri 0.9793, OMH değeri 0.1228, OKH değeri 0.0423 ve KOKH değeri 0.2057 olarak hesaplanmıştır. Yapılan çalışmanın sonucunda HVOF yöntemi ile Stellite-1 tozu ile kaplanan AZ91D magnezyum alaşımının aşınma kayıplarının tahmininde YSA' nın başarılı bir şekilde uygulanabileceği gözlemlenmiştir. Önerilen YSA modelinin HVOF ile yüzey kaplama sanayinde kullanılmasıyla yeni bir ürün tasarlarken gerekli olabilecek aşınma deneylerinden kaynaklı maliyet ve zaman kaybı azaltılabilir.

Tablo 4.2. YSA ile aşınma kayıplarının tahmin performansı

\begin{tabular}{|c|c|c|c|}
\hline R-değeri & OMH & OKH & KOKH \\
\hline 0.9793 & 0.1228 & 0.0423 & 0.2057 \\
\hline
\end{tabular}

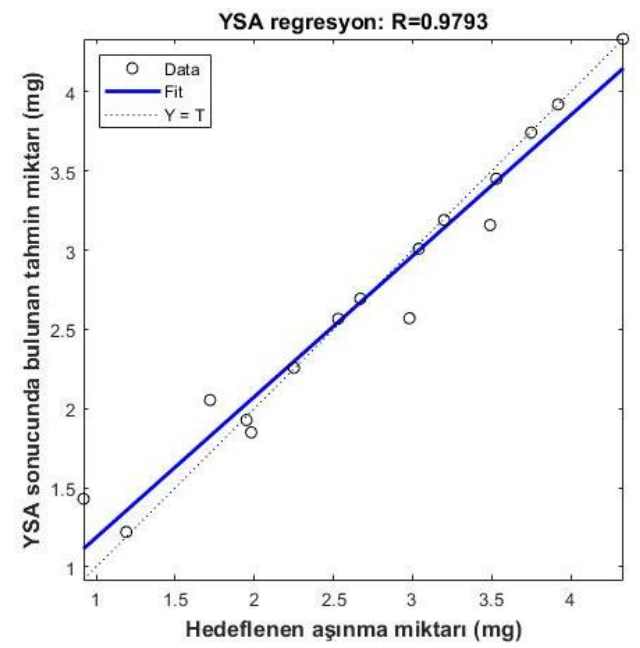

Şekil 4.1. Regresyon analiz grafiği.

\section{Sonuçlar}

- HVOF yöntemi ile farklı parametrelerde Stellite-1 tozu ile yüzeyi kaplanmış AZ91D magnezyum alaşımının aşınma kayıp miktarları önerilen YSA modeli ile tahmin edilebilmektedir.

- Önerilen model kullanılarak HVOF yöntemi ile gerçekleştirilen Stellite-1 kaplamaların aşınma deneyleri sonucunda ortaya çıkan, maliyet, zaman ve iş gücü kaybı azaltılabilir.

- YSA ile aşınma kayıpları başarılı bir şekilde tahmin edilmiş̧ir ve R-değeri 0.9793 hesaplanmıştır.

- Ortalama Mutlak Hata değeri 0.1228, Ortalama Kare Hata değeri 0.0423 ve Kök Ortalama Kare Hata değeri ise $0.2057^{\prime}$ 'dir.

\section{Kisaltmalar}

HVOF: Yüksek hizlı oksi-yakıt püskürtme

YSA: Yapay sinir ağları

AK: Aşıınma kaybı

OMH: Ortalama mutlak hata

OKH: Ortalama Kare Hata

KOKH: Kök Ortalama Kare Hata

\section{Kaynaklar}

[1] Tong L, Zhang J, Xu C, Wang X, Song S, Jiang Z, Kamado S, Cheng L, Zhang H. Enhanced corrosion and wear resistances by graphene oxide coating on the surface of Mg-Zn-Ca alloy. Carbon 2016; 109: 340-351 
[2] Cui L-Y, Gao S-D, Li P-P, Zeng R-C, Zhang F, Li S-Q, Han E-H. Corrosion resistance of a self-healing micro-arc oxidation/polymethyltrimethoxysilane composite coating on magnesium alloy AZ31. Corrosion Science 2017; 118: 8495

[3] Gnedenkov S, Sinebryukhov S, Mashtalyar D, Nadaraia K, Gnedenkov A, Bouznik V. Composite fluoropolymer coatings on the MA8 magnesium alloy surface. Corrosion Science 2016; 111: 175-185

[4] Praveen A S, Sarangan J, Suresh S, Channabasappa B. Optimization and erosion wear response of NiCrSiB/WC-Co HVOF coating using Taguchi method. Ceramics International 2016; 42(1): 1094-1104

[5] Özel C, Akgün G, Gürgenc T. Microstructure, wear and friction behavior of AISI 1045 steel surfaces coated with mechanically alloyed Fe16Mo2C0.25Mn/Al2O3-3TiO2 powders. Materials Testing 2017; 59(10): 921-928

[6] Deshpande P, Minfray C, Dassenoy F, Thiebaut B, Le Mogne T, Vacher B, Jarnias F. Tribological behaviour of TiO2 Atmospheric Plasma Spray (APS) coating under mixed and boundary lubrication conditions in presence of oil containing MoDTC. Tribology International 2018; 118: 273-286

[7] Kumar D, Murtaza Q, Singh R. Sliding wear behavior of aluminum alloy coating prepared by two-wire electric arc spray process. The International Journal of Advanced Manufacturing Technology 2016; 85(1-4): 237-252

[8] Zavareh M A, Sarhan A A D M, Razak B B, Basirun W J. The tribological and electrochemical behavior of HVOFsprayed Cr3C2-NiCr ceramic coating on carbon steel. Ceramics International 2015; 41(4): 5387-5396

[9] Dayani S, Shaha S, Ghelichi R, Wang J, Jahed H. The impact of AA7075 cold spray coating on the fatigue life of AZ31B cast alloy. Surface and Coatings Technology 2018; 337: 150-158

[10] Koga G, Schulz R, Savoie S, Nascimento A, Drolet Y, Bolfarini C, Kiminami C, Botta W. Microstructure and wear behavior of Fe-based amorphous HVOF coatings produced from commercial precursors. Surface and Coatings Technology 2017; 309: 938-944

[11] Picas J, Punset M, Rupérez E, Menargues S, Martin E, Baile M. Corrosion mechanism of HVOF thermal sprayed WCCoCr coatings in acidic chloride media. Surface and Coatings Technology 2018

[12] Parco M, Zhao L, Zwick J, Bobzin K, Lugscheider E. Investigation of HVOF spraying on magnesium alloys. Surface and Coatings Technology 2006; 201(6): 3269-3274

[13] López A, Torres B, Taltavull C, Rams J. Influence of high velocity oxygen-fuel spraying parameters on the wear resistance of Al-SiC composite coatings deposited on ZE41A magnesium alloy. Materials \& design 2013; 43: 144-152

[14] García-Rodríguez S, López A, Torres B, Rams J. 316L stainless steel coatings on ZE41 magnesium alloy using HVOF thermal spray for corrosion protection. Surface and Coatings Technology 2016; 287: 9-19

[15] Taltavull C, López A J, Torres B, Atrens A, Rams J. Optimisation of the high velocity oxygen fuel (HVOF) parameters to produce effective corrosion control coatings on AZ91 magnesium alloy. Materials and Corrosion 2015; 66(5): 423433

[16] Sawant M S,Jain N. Investigations on wear characteristics of Stellite coating by micro-plasma transferred arc powder deposition process. Wear 2017; 378: 155-164

[17] Hsu S M,Shen M. Wear prediction of ceramics. Wear 2004; 256(9-10): 867-878

[18] Altay O, Gurgenc T, Ulas M, Özel C. Prediction of wear loss quantities of ferro-alloy coating using different machine learning algorithms. Friction 2019: 1-8

[19] Fathy A,Megahed A. Prediction of abrasive wear rate of in situ $\mathrm{Cu}-\mathrm{Al} 2 \mathrm{O} 3$ nanocomposite using artificial neural networks. The International Journal of Advanced Manufacturing Technology 2012; 62(9-12): 953-963

[20] Kavimani V, Prakash K S, Thankachan T. Surface characterization and specific wear rate prediction of r-GO/AZ31 composite under dry sliding wear condition. Surfaces and Interfaces 2017; 6: 143-153

[21] Younesi M, Bahrololoom M, Ahmadzadeh M. Prediction of wear behaviors of nickel free stainless steel-hydroxyapatite bio-composites using artificial neural network. Computational Materials Science 2010; 47(3): 645-654

[22] Rashed F,Mahmoud T. Prediction of wear behaviour of A356/SiCp MMCs using neural networks. Tribology International 2009; 42(5): 642-648

[23] Sahraoui T, Guessasma S, Fenineche N, Montavon G, Coddet C. Friction and wear behaviour prediction of HVOF coatings and electroplated hard chromium using neural computation. Materials Letters 2004; 58(5): 654-660

[24] Hamzaçebi C,Kutay F. Yapay sinir ağlari ile Türkiye elektrik enerjisi tüketiminin 2010 yilina kadar tahmini. Gazi Üniversitesi Mühendislik-Mimarlık Fakültesi Dergisi 2004; 19(3)

[25] Esfe M H, Wongwises S, Naderi A, Asadi A, Safaei M R, Rostamian H, Dahari M, Karimipour A. Thermal conductivity of $\mathrm{Cu} / \mathrm{TiO} 2-$ water/EG hybrid nanofluid: Experimental data and modeling using artificial neural network and correlation. International Communications in Heat and Mass Transfer 2015; 66: 100-104

[26] Açikgenç M, Ulaş M, Alyamaç K E. Using an artificial neural network to predict mix compositions of steel fiberreinforced concrete. Arabian Journal for Science and Engineering 2015; 40(2): 407-419

[27] Yu X, Ye C, Xiang L. Application of artificial neural network in the diagnostic system of osteoporosis. Neurocomputing 2016; 214: 376-381 